\title{
Comparison of Various Clinical Methods of Birth Weight Estimation in Term Pregnancy
}

\author{
Darshit G Prajapati* and Riddhi M Patel \\ Department of Obstetrics \& Gynecology, GMERS medical college and hospital, India
}

*Corresponding author: Darshit G Prajapati, Department of Obstetrics \& Gynecology, GMERS medical college and hospital, Near Chhipwad Postoffice, Opp. Hanuman Temple, Chhipwad, Valsad, Gujarat, 396001, India.

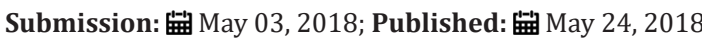

\begin{abstract}
Background: Knowledge of fetal weight in utero is vital for the obstetrician in deciding whether or not to deliver the fetus as well as in fixing the mode of delivery. Both low birth weight and excessive fetal weight at delivery are associated with increased risk of newborn complications during labor and the puerperium. Various clinical formulae like Johnson's formula \& Dare's formula are in use for fetal weight estimation.
\end{abstract}

Objectives: The aim of this study was to assess the fetal weight in term pregnancies by various clinical methods- Dare's formula \& Johnson's formula and to compare the methods after knowing the actual weight of the baby after birth.

Study Design: It is a prospective observational study of 227 women at term pregnancy at GMERS medical college \& Hospital, sola, Ahmadabad from April 2014 to April 2016. The formulas used in this study are: Johnson's formula and Dare's formula. The measurements were compared with actual birth weight after the birth of baby.

Results: Results vary in terms of accuracy with various methods employed for estimating the fetal weight. This study showed that Dare's formula was the best method for fetal birth weight estimation.

Conclusion: Dare's formula is an inexpensive method for fetal birth weight estimation. It continues to be used in many countries on large scale because of its low cost, ease of use, and need for little training as the setup for ultra sonographic evaluation is not readily available in rural setups.

Keywords: Dare's formula; Fetal birth weight; Johnson's formula

Abbreviations: ABW: Actual Birth Weight; AG: Abdominal Girthp; ANOVA: Analysis Of Variance; BMI: Body Mass Index; BW : Birth Weight; EBW : Estimated Birth Weight; GA: Gestational Age; SFH: Symphysio Fundal Height; SD : Standard Deviation; USG : Ultrasonography

\section{Introduction}

Accurate prenatal estimation of fetal weight in late pregnancy and labour permits obstetricians to make decisions about instrumental vaginal delivery, trial of labour after caesarean delivery and elective caesarean section for patients suspected of having a macrosomic fetus [1-5]. Both low birth weight and excessive birth weight at delivery are associated with increased risk of newborn complications during labour and puerperium [6]. Different methods of estimating fetal weight have been used and broadly they are classified as:

\section{Clinical methods}

Extensively used, convenient and virtually costless. Various clinical formulas like johnson's formula, dawn's formula and dare's formula are used for fetal weight estimation.

\section{Ultrasonography}

Several formulae have been developed for estimating fetal weight by ultrasound [4,7-10]. These formulae involve a variety of sonographically obtained biometric measurements. The most popular formulae are Shepard, Warsof's with Shepard's modification and Hadlock's. These formulae are included in most ultrasound equipment packages. In urban setup, ultrasound is easily available for birth weight estimation. In rural setup such imaging modality are not easily available and clinical methods are still used by health workers for birth weight estimation as clinical methods of birth weight estimation don't require any costly equipment and they are easy to use and give immediate estimation of expected birth weight.

\section{Materials and Methods}

The study was approved by Institutional ethical committee, GMERS medical college sola, Ahmedabad. The study was conducted in Obstetrics and Gynecology Department, GMERS Medical College Hospital Sola, Ahmadabad. Antenatal patients with singleton live cephalic fetus with gestational age between 37 to 40 weeks attending Obstetrics and Gynecology Department of GMERS Medical College Hospital Sola, Ahmadabad were included over a period of 2 year from April 2014 to April 2016.

Copyright $\odot$ All rights are reserved by Darshit G Prajapati. 
This was a prospective observational type of study. The prevalence of full term antenatal patient in our institute was 30\%. So with $90 \%$ confidence interval and $5 \%$ allowable error, the desired sample size was as follows

$$
\begin{aligned}
& \mathrm{N}=\mathrm{p}(1-\mathrm{p}) \times \mathrm{Z} \div(\mathrm{me})^{2} \\
& \text { Where, } \mathrm{N}=\text { sample size } \\
& \mathrm{p}=\text { prevalence } 30 \% \\
& \mathrm{z}=\text { confidential limit which is } 90 \%=1.645 \\
& \text { me=margin of error }-5 \%
\end{aligned}
$$

So,

$\mathrm{N}=0.30(0.70)(1.645)^{2} \div(0.05)^{2}=227$

\section{Inclusion criteria}
a) Single live fetus
b) Gestational age between 37 to 40 weeks
c) Cephalic presentation

\section{Exclusion criteria}
a) Multiple Gestation
b) Malpresentation
c) Polyhydramnios
d) Oligohydramnios
e) Intrauterine Growth Retardation
f) Fibroids or Adnexal Mass
g) Congenital Anomalies

\section{Methodology}

227 antenatal patients were included in our study as per inclusion criteria. All the eligible patients were given patient information sheet and were included in study after obtaining written informed consent. The patient was then asked to empty her bladder and her symphysiofundal height (SFH) and abdominal girth (AG) were measured using a flexible, non-elastic, standard measure tape. Both measurements were performed with the patient lying flat on her back, with her legs extended. The SFH was measured from the midpoint of the upper border of the pubic symphysis to the highest point of the uterine fundus. For the AG measurement, the tape was repositioned to encircle the woman's waist, at the level of the umbilicus, without applying pressure to tighten the tape around the abdomen. Then pelvic examination was performed to evaluate degree of descent (station) of the fetal head into the pelvis. Both measurements (SFH and AG) and information on the fetal station were recorded on the individual data sheet and later used to calculate the fetal weight according following formula;
A. Dare's formula: Weight in grams=AGxSFH
B. Johnson's formula: Weight in grams=155x(SFH-X)

$\mathrm{X}=13$ when presenting part at minus station

\section{$\mathrm{X}=12$ when presenting part is at 0 station \\ $\mathrm{X}=11$ when presenting part is at plus station}

Immediately after delivery, Actual Birth Weight (ABW) was measured using a digital balance. If delivery did not occur within a week of estimations, the estimations were repeated and repeat estimations were taken in to consideration. Estimated Birth Weight (EBW) calculated by using various methods was compared with actual birth weight after the birth of baby.

The average error, average percentage error, correlation of coefficient, standard deviation of prediction error and $P$ value were calculated with the help of statistician and analysis was done. A P value $<0.05$ was considered significant. Student paired $t$ test was used for comparison of various method of birth weight estimation with actual birth weight. Analysis of variance (ANOVA) test was used for comparison of different methods of birth weight estimations with each other.

\section{Results}

The demographic characteristics of the study population are shown in Table 1 . In our study the mean maternal age was $25.63 \pm 3.68$ years and the median was 25 years (range 18-35 years). The mean parity was $0.89 \pm 0.82$ and the median was 1 (range $0-3$ ). The mean maternal BMI was $21.57 \pm 2.49 \mathrm{~kg} / \mathrm{m}^{2}$ and the median was $21.51 \mathrm{~kg} / \mathrm{m}^{2}$ (range $15.4 \mathrm{~kg} / \mathrm{m}^{2}-31.39 \mathrm{~kg} / \mathrm{m}^{2}$ ). The mean gestational age at the time of delivery was $38.73 \pm 0.83$ weeks and the median was 38.6 weeks (range 37-40 weeks). Table 2 shows mean error of overestimation and underestimation by various clinical methods. Mean error in over and under estimations was more in Johnson's formula than Dare's formula. Mean error of over estimation were 166.30gm and 324.31gm for Dare's formula and Johnson's formula respectively. In case of under estimation, mean error was least with Dare's formula as compared to other method. (101.33gm and 111.25gm for Dare's formula and Johnson's formula respectively).

Table 1: Demographic characteristics of study population.

\begin{tabular}{|c|c|c|c|}
\hline Characteristics & Mean \pm SD & Median & Range \\
\hline Maternal Age (year) & $25.63 \pm 3.68$ & 25 & $18-35$ \\
\hline Parity & $0.89 \pm 0.82$ & 1 & $0-3$ \\
\hline BMI $\left(\mathrm{kg} / \mathrm{m}^{2}\right.$ ) & $21.57 \pm 2.49$ & 21.51 & $15.4-31.39$ \\
\hline $\begin{array}{c}\text { Gestational Age at } \\
\text { delivery (weeks) }\end{array}$ & $38.73 \pm 0.83$ & 38.6 & $37-40$ \\
\hline
\end{tabular}

Table 2: Mean error of overestimation and underestimation by various clinical methods.

\begin{tabular}{|c|c|c|}
\hline \multirow{2}{*}{ Method } & \multicolumn{2}{|c|}{ Mean Error(gm) } \\
\cline { 2 - 3 } & Over estimation & Under estimation \\
\hline Dare's formula & 166.3 & 101.33 \\
\hline Johnson's formula & 324.31 & 111.25 \\
\hline
\end{tabular}

Table 3 shows the mean fetal weight measured by clinical and ultrasound methods. Mean actual birth weight at the time of delivery was $2827 \pm 365 \mathrm{gm}$ in study population. Maximum ABW was $4120 \mathrm{gm}$ while minimum was $2125 \mathrm{gm}$ in present study. The mean estimated birth weights (EBW) by Dare's formula and Johnson's 
formula were $2920 \pm 355 \mathrm{gm}$ and $3112 \pm 346 \mathrm{gm}$ respectively. It was also found that actual birth weight was significantly different from clinically estimated weight. ( $\mathrm{T}$ test $=8.781$, $\mathrm{P}$ value $<0.0001$ and
T test=19.897, $\mathrm{P}$ value $<0.0001$ for Dare's formula and Johnson's formula respectively)

Table 3: The mean fetal weight measured by various methods.

\begin{tabular}{|c|c|c|c|c|c|c|}
\hline Method & N & Mean \pm SD & Minimum & Maximum & Paired T Test & P value \\
\hline EBW by Dare's formula (gm) & 227 & $2920 \pm 355$ & 2100 & 4000 & 8.781 & $<0.0001$ \\
\hline EBW by Johnson's formula (gm) & 227 & $3112 \pm 346$ & 2170 & 4185 & 19.897 & $<0.0001$ \\
\hline
\end{tabular}

Table 4: The errors in Birth weight estimation by various methods compared to actual birth weight.

\begin{tabular}{|c|c|c|c|}
\hline Error & Dare's Formula & Johnson's Formula & P value of ANOVA \\
\hline Mean error(gm) & $-92.92 \pm 159.43$ & $-284.51 \pm 215.43$ & $<0.0001$ \\
\hline Mean absolute error(gm) & $147.37 \pm 110.78$ & $304.11 \pm 186.60$ & $<0.0001$ \\
\hline Mean percentage error(\%) & $-3.510 \pm 5.688$ & $-10.529 \pm 7.983$ & $<0.0001$ \\
\hline Mean absolute percentage error(\%) & $5.298 \pm 4.067$ & $11.091 \pm 7.178$ & $<0.0001$ \\
\hline
\end{tabular}

Table 4 shows the errors in Birth weight estimation by various methods compared to actual Birth weight. The mean error for Dare's formula and Johnson's formula were $-92.92 \pm 159.43 \mathrm{gm}$ and $-284.51 \pm 215.43 \mathrm{gm}$ respectively. (Difference was statistically significant as $\mathrm{P}$ value $<0.0001$ ) The mean absolute error for Dare's formula and Johnson's formula were 147.37 $\pm 110.78 \mathrm{gm}$ and $304.11 \pm 186.60 \mathrm{gm}$ respectively. (Difference was statistically significant as $\mathrm{P}$ value $<0.0001$ ). The mean percentage error for Dare's formula and Johnson's formula were $-3.510 \pm 5.688 \%$ and $-10.529 \pm 7.983 \%$ respectively. (Difference was statistically significant as $\mathrm{P}$ value $<0.0001$ ). The mean absolute percentage error for Dare's formula and Johnson's formula were $5.298 \pm 4.067 \%$ and $11.091 \pm 7.178 \%$ respectively. (Difference was statistically significant as $P$ value $<0.0001$ ).

Table 5: Error in percentage related to various methods.

\begin{tabular}{|c|c|c|}
\hline Error & Dare's Formula & Johnson's Formula \\
\hline$<10 \%$ & $\mathrm{~N}=227$ & $\mathrm{~N}=227$ \\
\hline $10-20 \%$ & $205(90.31 \%)$ & $111(48.90 \%)$ \\
\hline$>20 \%$ & $19(8.37 \%)$ & $91(40.09 \%)$ \\
\hline
\end{tabular}

Table 5 shows error in percentage related to various methods of birth weight estimations. Estimations with error of $<10 \%$ of ABW were most with Dare's formula (90.31\%). Johnson's formula had least number of such cases (only 48.90\%). This difference was statistically significant. (P value 0.0000 by Chi square test). Estimations with error between 10 to $20 \%$ and $>20 \%$ of ABW were most with Johnson's formula compared to the other method. The correlation coefficient for the Dare's formula and Johnson's formula compared to actual birth weight were +0.9026 and +0.8182 respectively, showing positive correlation with ABW. So the strongest positive correlation with ABW was observed for Dare's formula.

\section{Comments}

\section{Main findings and comparison with existing literature}

Numbers of articles had been published in various journals regarding comparison of various method of birth weight estimation. They also include USG as one of the method of birth weight estimation. Raghuvanshi et al. [11] had found that mean of estimated fetal weight by Dare's formula (2696 $\pm 394.2 \mathrm{gm})$ were almost closer to the mean of actual birth weight $(2593 \pm 427 \mathrm{gm})$ but comparing it with $\mathrm{ABW}$, difference was found statistically significant. (P value was 0.01) Amritha et al. [12] had conducted a study for comparative analysis of accuracy of various method of birth weight estimation on 200 antenatal women. Standard deviation of prediction error was less with Dare's formula compared to Johnson's formula in their study (272.66 gm compared to $309.98 \mathrm{gm}$ ) In present study, the mean error for Dare's formula and Johnson's formula were $-92.92 \pm 159.43 \mathrm{gm}$ and $-284.51 \pm 215.43 \mathrm{gm}$ respectively (statistically significant as $\mathrm{P}$ value $<0.0001$ ).Maximum error in estimated birth weight was found highest with Johnson's formula between two clinical methods in studies conducted by Amritha et al. [12] and Raghuvanshi et al. [11] (1135gm and 1771gm respectively). In present study, maximum error was found highest with Johnson's formula (980gm). Amritha et al. [12] had found that Dare's formula had least average error (224.37gm) between two clinical methods of birth weight estimations. In present study, least average error (147.37 $\pm 110.78 \mathrm{gm})$ was found with Dare's formula estimated EBW. Number of cases with accuracy of fetal estimates within $10 \%$ of ABW was higher with Dare's formula in study conducted by Raghuvanshi et al. [11] (65\%) and Amritha et al. [12] (67\%). In present study we found $89.43 \%$ of cases with error of $<10 \% \mathrm{ABW}$ with Dare's formula. Johnson's formula had only $48.46 \%$ of cases with fetal birth weight estimates within $10 \%$ of ABW.

\section{Strength and limitation of study}

Strength: This study compared various clinical methods which are cost effective and easy to use. It can be performed easily by any medical personnel requiring no specialized training. 
Limitation: Sample size of present study was small and present study was conducted in single center. Multi centric study should be conducted to validate the observation made in our study. Present study included full term babies with cephalic presentation without any complication. Application of this data may not be useful in determining low birth weight babies in complicated pregnancy. It is necessary to conduct study to verify its usefulness in detecting low birth weight babies.

\section{Conclusion and implications}

Among the clinical methods, Dare's formula is more accurate than Johnson's formula. Average error in estimated birth weight compared to ABW is least with Dare's formula. Dare's formula is more accurate in estimating birth weight within $10 \%$ of ABW as compared to Johnson's formula. Both methods of birth weight estimations in our study have positive linear correlation with ABW. As the actual birth weight increases the estimation of birth weight by clinical methods also increases. In all term pregnant women, birth weight should be estimated before delivery as it helps us to predict maternal and perinatal outcome. In low resource settings, the Dare's formula should be used as against the Johnson's formula for estimating birth weight.

\section{Acknowledgement}

We thank our colleagues and seniors from GMERS medical college sola, Ahmadabad who provided insight and expertise that greatly assisted the research.

\section{Disclosure Statement}

We hereby transfer or assign all copyright ownership, including any and all rights incidental thereto, exclusively to the Journal, in the event that such work is published by the Journal. We hereby indemnify your journal against any claims made by other parties concerning the authorship of the article or rights to publish the article. We have no conflict of interest. We give the rights to the corresponding author to make necessary changes or any correspondence with the journal on our behalf. He will act as the guarantor for the manuscript on our behalf.

\section{References}

1. Baum JD, Gussman D, Wirth JC $3^{\text {rd }}$ (2002) Clinical and patient estimation of fetal weight vs. ultrasound estimation. J Reprod Med 43(3): 194-198.

2. Chauhan SP, Hendrix NW, Magann EF, Morrison JC, Kenney SP, et al. (1998) Limitations of clinical and sonographic estimates of birth weight: experience with 1,034 parturients. Obstetrics and Gynecology 91(1): 72-77.

3. Kurmanavicius J,burkhardt T, Wisser J, Huch R (2004) Ultrasonographic fetal weight estimation: accuracy of formulas and accuracy of examiners by birth weight from 500 to 5000g. Journal of Perinatal Medicine 32(2): 155-161.

4. Ben-Haroush A, Yogev Y, Bar J, Mashaich R, Kaplan B, et al. (2004) Accuracy of sonographically estimated fetal weight in 840 women with different pregnancy complications prior to induction of labor. Ultrasound Obstet Gynecol 23(2): 172-176.

5. McIntire DD, Bloom SL, Casey BM, Leveno KJ (1999) Birth weight in relation to morbidity and mortality among newborn infants. $\mathrm{N}$ Engl J Med 340(16): 1234-1238.

6. Jolly MC, Sebire NJ, Harris JP, Regan L, Robinson S (2003) Risk factors for macrosomia and its clinical consequences: a study of 350, 311 pregnancies. Eur J Obstet Gynecol Reprod Biol 111(1): 9-14.

7. Campbell S, Thomas A (1977) Ultrasound measurement of the fetal head to abdominal circumference ratio in the assessment of fetal growth retardation. Br J Obstet Gynaecol 84(3): 165-174.

8. Campbell S, Wilkin D (1975) Ultrasonic measurement of the fetal abdominal circumference in estimation of fetal weight. Br J Obstet Gynecol 82(9): 689-697.

9. Hadlock FP, Harrist RB, Carpenter RJ, Deter RL, Park SK (1984) Sonographic estimation of fetal weight. The value of femur length in addition to head and abdominal measurements. Radiology 150(2): 535540 .

10. Nzeh DA, Rimmer S, Moore WMO, Hunt L (1992) Prediction of birth weight by fetal ultrasound biometry. Br J Radiol 65(779): 987-989.

11. Raghuvanshi T, Milind P, Amol P (2014) Comparative study of fetal weight estimation by various methods among term pregnancies at rural tertiary care centre. Journal of Evolution of Medical and Dental Sciences 3(41): 10291-10296.

12. Bhandary Amritha A, Pinto Patric J, Shetty Ashwin P (2004) Comparative study of various methods of fetal weight estimation at term pregnancy. J Obstet Gynecol Ind 54(4): 336-339.
Creative Commons Attribution 4.0 International License

For possible submissions Click Here

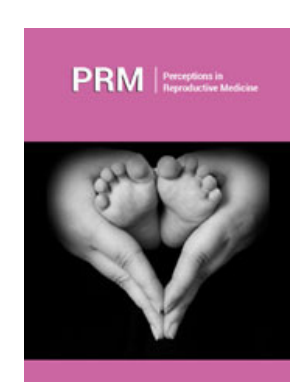

Perceptions in Reproductive Medicine

\section{Benefits of Publishing with us}

- High-level peer review and editorial services

- Freely accessible online immediately upon publication

- Authors retain the copyright to their work

- Licensing it under a Creative Commons license

- Visibility through different online platforms 